Pharma, and Pfizer, H. Yamanaka Grant/research support from: UCB Pharma, AbbVie, Astellas, Bristol-Myers Squibb, Chugai, Eisai, Janssen, Mitsubishi Tanabe, Pfizer, and Takeda, Consultant for: UCB Pharma, AbbVie, Astellas, Bristol-Myers Squibb, Chugai, Eisai, Janssen, Mitsubishi Tanabe, Pfizer, and Takeda, T. Yoneda Consultant for: Daiichi Sankyo, S. Tanaka Consultant for: Amgen inc, Amgen Astellas, KYOCERA Medical, Daiichi Sankyo, Teijin Pharma, Asahi Kasei Pharma, Ono Pharmaceutical, Eli Lilly, and Pfizer, T. Nitta Employee of: Daiichi Sankyo, N. Okubo Shareholder of: Daiichi Sankyo, Employee of: Daiichi Sankyo, H. K. Genant Consultant for: Daiichi Sankyo, Pfizer, Amgen, BioClinica, Eli-Lilly, Janssen, Servier, Novartis, Takeda, Merck, Biomarin, Clemencia, Agnovos, and Regeneron, D. van der Heijde Consultant for: AbbVie, Amgen, Astellas, AstraZeneca, BMS, Boehringer Ingelheim, Celgene, Daiichi Sankyo, Eli-Lilly, Galapagos, Gilead, Janssen, Merck, Novartis, Pfizer, Regeneron, Roche, Sanofi, and UCB Pharma, Employee of: Imaging Rheumatology bv DOI: 10.1136/annrheumdis-2017-eular.1081

\section{SAT0187 SAFETY, PHARMACOKINETICS AND EFFICACY OF E6011, AN ANTI-FRACTALKINE MONOCLONAL ANTIBODY, IN A FIRST-IN-PATIENT PHASE 1/2 STUDY IN RHEUMATOID ARTHRITIS; ADDTIONAL DATA OF 400 MG COHORT}

Y. Tanaka ${ }^{1}$, T. Takeuchi ${ }^{2}$, H. Umehara ${ }^{3}$, T. Nanki ${ }^{4}$, N. Yasuda ${ }^{5}$, F. Tago ${ }^{6}$, Y. Kitahara ${ }^{6}$, M. Kawakubo ${ }^{6}$, S. Hojo ${ }^{6}$, T. Kawano ${ }^{5}$, T. Imai ${ }^{5}{ }^{1}$ University of Occupational and Environmental Health, Japan, Kitakyushu; ${ }^{2}$ Keio University, Tokyo; ${ }^{3}$ Division of Rheumatology and Immunology, Nagahama City Hospital, Shiga; ${ }^{4}$ School of Medicine, Faculty of Medicine, Toho University, Tokyo; ${ }^{5}$ KAN Research Institute, Inc., Kobe; ${ }^{6}$ EISAI Co. Ltd., Tokyo, Japan

Background: Fractalkine (CX3CL1, designated as FKN hereafter) is the sole member of the CX3C-chemokine which leads to dual actions, chemotaxis and cell adhesion for leukocytes expressing the cognate receptor, CX3CR1, during their migration. Accumulating evidence is telling that FKN-CX3CR1 axis plays a pivotal role in leukocyte/lymphocyte accumulation in inflamed tissues in RA ${ }^{1}$. Last year, we presented an interim report (up to $200 \mathrm{mg}$ cohort) of Phase 1/2 study of E6011, a novel humanized anti-FKN monoclonal antibody, for active Japanese RA patients ${ }^{2}$.

Objectives: To evaluate safety, pharmacokinetics and efficacy of E6011 with the dosage up to $400 \mathrm{mg}$ in a Phase $1 / 2$, open-label, multiple ascending dose study in RA patients (NCT02196558).

Methods: Active RA patients with inadequate response (IR) to MTX or TNF inhibitors (TNFi) were received 7 consecutive doses (subcutaneous) of E6011 at week $0,1,2$ and thereafter every 2 weeks up to week 10 . The safety, pharmacokinetics and efficacy up to week 12 were evaluated.

Results: Twelve, 15 and 10 subjects were enrolled in the cohort of 100,200 and $400 \mathrm{mg}$ dosage, respectively, in total 37 subjects received repeated subcutaneous (SC) administrations of E6011. As a result, repeated dose of E6011 was found safe and well tolerated. The incidence of adverse event (AE), treatment-related $A E$ and serious $A E$ were $56.8 \%, 29.7 \%$ and $5.4 \%$, respectively. AEs occurring in $\geq 2$ subjects were nasopharyngitis, Injection site erythema, headache and oropharyngeal pain, among which there were no severe AEs, serious infections and deaths. No significant differences were observed in the incidence or severity of AEs across the cohorts.

After starting multiple SC injection of E6011, serum E6011 concentration reached steady-state at week 2, and its level was maintained up to week 12 in all cohorts. Clinical outcome was also available in the study in which response rates of ACR20, 50 and 70 at week 12 calculated using the non-responder imputation (NRI) were $75.0 \%, 33.3 \%, 8.3 \%$ in $100 \mathrm{mg}$ cohort, $66.7 \%, 20.0 \%, 13.3 \%$ in $200 \mathrm{mg}$ cohort and $60.0 \%, 30.0 \%, 20.0 \%$ in $400 \mathrm{mg}$ cohort, respectively. The percentage of patients categorized "good response" with the EULAR response criteria at week 12 (NRI) were $16.7 \%$ in $100 \mathrm{mg}$ cohort, $20 \%$ in $200 \mathrm{mg}$ cohort and $40 \%$ in $400 \mathrm{mg}$ cohort.

Conclusions: E6011 was safe and well tolerated, and the study demonstrated

Bar Chart of ACR Response Rate at Week 12 (NRI) Full Analysis Set

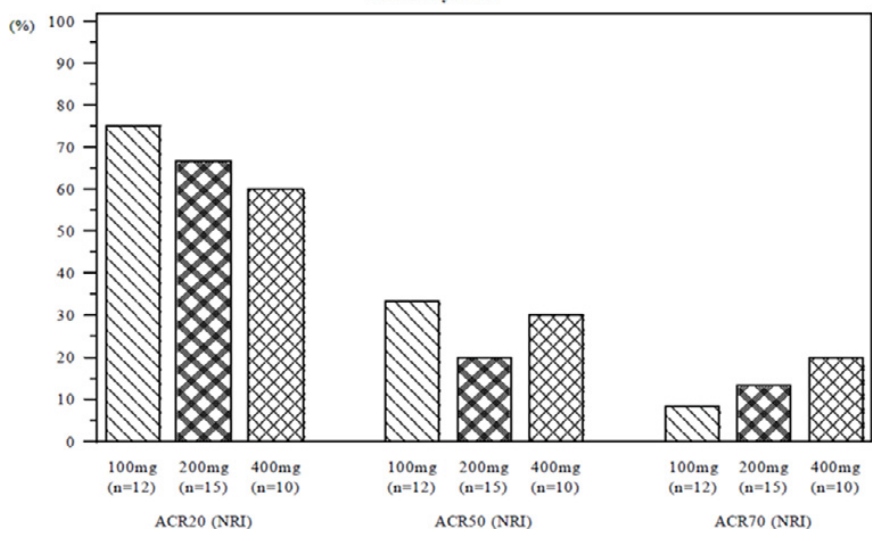

a promising efficacy of E6011 in active RA patients with MTX- or TNFi-IR. The results obtained suggest that a novel approach to target FKN/CX3CR1 interaction will be clinically beneficial for RA, and support to conduct phase 2 clinical trials in which the efficacy and safety should be confirmed in a placebo controled double-blind manner.

\section{References:}

[1] Nanki T. Arthritis Rheum. 2002; 46(11):2878-83.

[2] Tanaka Y, et al., EULAR Congress 2016, Poster Number FRI0236.

Acknowledgements: The authors wish to thank the study investigators.

Disclosure of Interest: Y. Tanaka Grant/research support from: MitsubishiTanabe, Takeda, Daiichi-Sankyo, Chugai, Bristol-Myers, MSD, Astellas, Abbvie, Eisai, Speakers bureau: Abbvie, Chugai, Daiichi-Sankyo, Bristol-Myers, MitsubishiTanabe, Astellas, Takeda, Pfizer, Teijin, Asahi-kasei, YL Biologics, Sanofi, Janssen, Eli Lilly, GlaxoSmithKline, T. Takeuchi Grant/research support from: Astellas, Bristol-Myers, Chugai, Daiichi-Sankyo, Eisai, AYUMI, Takeda, Teijin, AbbVie, Asahikasei, Taisho-Toyama, Consultant for: Astra Zeneca, Eli Lilly, Novartis, Mitsubishi-Tanabe, Asahi-Kasei, AbbVie, Daiichi-Sankyo, Bristol-Myers, Nipponkayaku, Janssen, Merck Serono, Takeda, Astellas, Pfizer, Speakers bureau: AbbVie, Bristol-Myers, Chugai, Eisai, Janssen, Mitsubishi-Tanabe, Pfizer, Takeda, Astellas, Daiichi-Sankyo, Celtrion, Nipponkayaku, H. Umehara: None declared, T. Nanki Grant/research support from: Chugai, Eisai, Takeda, Teijin, Eli Lilly, Bristol-Myers, AbbVie, Ono, Novartis, Asahi-Kasei, Consultant for: UCB, Eisai, Chugai, Speakers bureau: Mitsubishi-Tanabe, Chugai, Eisai, Takeda, Astellas, Janssen, Eli Lilly, Ayumi, Pfizer, Ono, AbbVie, N. Yasuda Shareholder of: EISAI, Employee of: EISAI, F. Tago Employee of: EISAI, Y. Kitahara Shareholder of: EISAI, Employee of: EISAI, M. Kawakubo Shareholder of: EISAI, Employee of: EISAI, S. Hojo Employee of: EISAI, T. Kawano Employee of: KAN Research Institute, T. Imai Employee of: KAN Research Institute DOI: 10.1136/annrheumdis-2017-eular.1401

\section{SAT0188 FIRST-LINE TREATMENT PATTERNS OF PATIENTS WITH RHEUMATOID ARTHRITIS WHO ARE ANTI-CYCLIC CITRULLINATED PEPTIDE ANTIBODY POSITIVE VERSUS NEGATIVE}

K. Price ${ }^{1}$, Y. Doleh ${ }^{1}$, M. Eaddy ${ }^{2}$, A. Ogbonnaya ${ }^{2}$, H.-C. Shih ${ }^{2}$, H. Ahmad ${ }^{1}$, L. Lamerato ${ }^{3}$, A. Szymialis ${ }^{1}{ }^{1}$ Bristol-Myers Squibb, Princeton; ${ }^{2}$ Xcenda, LLC, Palm Harbor; ${ }^{3}$ Henry Ford Health System, Detroit, United States

Background: Patients with RA who are at a higher risk for progressive and destructive arthritis could be identified using anti-cyclic citrullinated peptide (anti-CCP) levels. ${ }^{1}$ Treatment guidelines recommend the use of non-biologic DMARDs as initial treatment in RA; but, if warranted, biologic (b)DMARDs could be considered in early treatment of RA. ${ }^{2}$ Real-world data describing treatment patterns based on anti-CCP designations are limited.

Objectives: This study evaluated treatment patterns of patients with RA who are anti-CCP positive $(+)$ or negative $(-)$.

Methods: This retrospective study was based on electronic medical record (EMR) data with a supplemental chart review from a large integrated delivery system. Patients newly diagnosed with RA (International Classification of Diseases, Ninth Revision, Clinical Modification diagnosis code 714.0x) were identified between 1 January 2009 and 31 December 2014. The first RA diagnosis date was designated as the index date. Patients were required to have 12 months of continuous activity in the EMR (6 months pre- and 6 months post-index). Based on the baseline anti-CCP test results, patients were categorized as anti-CCP+ $(>7.0 \mathrm{U})$ or antiCCP- $(<7.0 \mathrm{U})$. First-line therapy (time to treatment initiation, treatment regimen, treatment changes and response to treatment) was evaluated in the post-index period. Response to treatment was determined based on physicians' notes.

Results: Overall, 217 anti-CCP+ and 191 anti-CCP- patients with RA were included in this study. A higher proportion of anti-CCP+ $(153,70.5 \%)$ than antiCCP-patients $(44,23.0 \% ; \mathrm{p}<0.0001)$ initiated treatment, generally within 1 month after diagnosis (anti-CCP+, mean [SD]: 31.1 [42.1] days and anti-CCP-, 28.1 [37.4] days; $p=0.6538$ ). MTX was most commonly used as first-line therapy. More anti-CCP+ than anti-CCP- patients received MTX (73.2 vs $56.8 \%$; $\mathrm{p}=0.0374)$, while more anti-CCP-than anti-CCP+ patients received hydroxychloroquine (31.8 vs $13.1 \% ; p=0.0037$ ). Only three anti-CCP+ and no anti-CCP- patients were treated with a bDMARD. Response to treatment was similar between the cohorts $(p=0.2444) ; 22.9 \%$ of anti-CCP+ and $18.2 \%$ of anti-CCP-patients had a complete response to the first-line therapy, and $33.3 \%$ of anti-CCP+ and $25.0 \%$ of antiCCP- patients had a partial response to the first-line therapy. Treatment change, however, significantly differed between the two cohorts ( $p=0.0058) ; 11.1$ and $9.1 \%$ of patients discontinued, 9.8 and $9.1 \%$ of patients switched, and 3.9 and $9.1 \%$ of patients augmented in the anti-CCP+ and anti-CCP- cohorts, respectively. Treatment changes occurred approximately 3 months after treatment initiation (anti-CCP+, 82.0 [49.7] days and anti-CCP-, 83.8 [52.7] days; $\mathrm{p}=0.9178$ ).

Conclusions: After diagnosis of RA, patients who are anti-CCP+ were more likely to start therapy, indicating that physicians were more aggressive in treating this cohort. Patients were treated according to guidelines with non-biologic DMARDs, predominantly MTX. Patterns of treatment change differed between the cohorts; however, treatment response was similar with a complete response rate of $20 \%$. References:

[1] Singh JA, et al. Arthritis Rheumatol 2016;68:1-26.

[2] Niewold TB, et al. QJM 2007;100:193-201. 
Disclosure of Interest: K. Price Employee of: Bristol-Myers Squibb, Y. Doleh Employee of: Bristol-Myers Squibb, M. Eaddy Consultant for: Xcenda, A. Ogbonnaya Employee of: Xcenda, H.-C. Shih Employee of: Xcenda, H. Ahmad Shareholder of: Bristol-Myers Squibb, Employee of: Bristol-Myers Squibb, L. Lamerato Grant/research support from: Centers for Disease Control, National Cancer Institute, Policy Analysis, Inc, Outcomes Research Solutions, Xcenda, eMAXHealth, Merck Pharmaceuticals, Pfizer Pharmaceuticals, Reagan Udall Foundation, AstraZeneca, Employee of: Henry Ford Health System, University of Michigan-Dearborn, A. Szymialis Shareholder of: Bristol-Myers Squibb, Employee of: Bristol-Myers Squibb

DOI: 10.1136/annrheumdis-2017-eular.1794

\section{SAT0189 FACTORS INFLUENCING THE PRESCRIPTION OF TOCILIZUMAB ALONE OR IN COMBINATION WITH DMARDS IN RHEUMATOID ARTHRITIS PATIENTS IN A REAL LIFE SETTING. POOLED ANALYSIS OF 3 OBSERVATIONAL STUDIES}

A. Saraux ${ }^{1}$, A. Cantagrel ${ }^{2}$, B. Combe ${ }^{3}$, R.-M. Flipo ${ }^{4}$, I. Idier ${ }^{5}$, C. Baffie ${ }^{6}$, J. Tebib ${ }^{7} .{ }^{1}$ Rheumatology, University Hospital, Brest; ${ }^{2}$ Rheumatology, University Hospital, Toulouse; ${ }^{3}$ Rheumatology, University Hospital, Montpellier; ${ }^{4}$ Rheumatology, University Hospital, Lille; ${ }^{5}$ Medical, Chugai Pharma France, Paris la Defense; ${ }^{6}$ Statistics, Roche SAS, Boulogne; ${ }^{7}$ Rheumatology, University Hospital, Lyon, France

Background: Tocilizumab (TCZ) as monotherapy (Mono) is nowadays a standard treatment in rheumatoid arthritis (RA) for patients in whom methotrexate (MTX) is inappropriate ${ }^{1}$

Objectives: To describe factors influencing the use of TCZ in Mono or in combination with DMARDs (Combo) in real-life practice in RA patients (pts).

Methods: Analysis: pooled data of 3 prospective, multicentre, observational studies (PEPS $n=610$, Spare- $1 n=307$, Act-solo $n=577$ ). Patients: RA pts requiring TCZ treatment according to their physician. Treatment: TCZ as prescribed in real life. Endpoint: Evaluation of factors influencing the use of TCZ in Mono or in Combo. Data collected: demographic characteristics, past medical history, RA characteristics and history including previous RA treatments, TCZ treatment strategy (Mono or Combo). Statistical analysis: Pts fulfilling inclusion and noninclusion criteria and with $\geq 1 \mathrm{TCZ}$ infusion were analyzed. 1- descriptive analysis 2- Univariate and multivariate analysis to determine factors influencing the use of TCZ in Mono. Variables with more than $20 \%$ of missing data were excluded from the multivariate model.

Results: 1494 pts ( 3 studies) were analysed at inclusion. Pts' characteristics: $56 \%$ of the pts were $>55$ years old, $79.6 \%$ female, mean RA duration $11.1 \pm 9.3$ years, $83.0 \%$ positive for rheumatoid factors and/or ACPA, $77.3 \%$ with erosive disease on X-rays, mean ESR $29.9+23.1 \mathrm{~mm}$, mean CRP $19.9+26.2 \mathrm{mg} / \mathrm{l}$ mean DAS 28-ESR $5.21 \pm 1.22$, mean HAQ-DI $1.56 \pm 0.68$, and mean pain VAS $61.5 \pm 23.2$. Past RA treatment included csDMARDs in $98.5 \%$ and biologics in $77.8 \%$ (median $=2$ [1-6]). TCZ was initiated as Mono in $36.4 \%$ of pts and in Combo in $63.6 \%$, with MTX in $83.3 \%$ of Combo pts (mean dose $15.7 \pm 4.4 \mathrm{mg} / \mathrm{week}$ ). Corticosteroids were used in $74 \%$ of pts (mean dose $10 \pm 7 \mathrm{mg} /$ day). Variables associated with a TCZ prescription in Mono were age ( $\geq 65$ years), number of previous bDMARD, use/dose of steroids, ESR/CRP values, VAS global activity (physician and pt), pain VAS and HAQ-DI. In the multivariate analysis, variables associated with a TCZ prescription in Mono were age $\geq 65$ years $(\mathrm{OR}=1.71$ [1.30 - 2.24], $p<0.001)$, number of previous bDMARD ( 1 bDMARD, OR=1.35 [0.94 - 1.92], 2 bDMARD OR=1.82 [1.28 - 2.60], $\geq 2$ bDMARD, OR=1.19 [0.82 - 1.71] $p=0.006)$, higher pain VAS $(\mathrm{OR}=1.09$ [1.04 - 1.15], $p=0.001)$, higher ESR value ( $O R=1.07$ [1.02 - 1.12], $p=0.013)$.

Conclusions: This pooled analysis suggests that physicians preferably prescribe TCZ alone in older patients, heavily treated before, with higher inflammatory markers and higher pain VAS. This use might be explained by physicians' reluctance to prescribe the association in frailer patients and complementary data on comorbidity factors will be analysed to support this hypothesis.

References:

[1] JS. Smolen et al, Ann Rheum Dis doi:10.1136/annrheumdis-2013-204573. Disclosure of Interest: A. Saraux: None declared, A. Cantagrel: None declared, B. Combe Consultant for: Chugai Pharma France, R.-M. Flipo Consultant for: Chugai Pharma France, I. Idier Employee of: Chugai Pharma France, C. Baffie Employee of: Altizem for Roche SAS, J. Tebib: None declared DOI: 10.1136/annrheumdis-2017-eular.2916

\section{SAT0190 ESTIMATE OF CLINICAL AND ANTIDESTRUCTIVE EFFECTS OF RITUXIMAB IN RHEUMATOID ARTHRITIS}

A.V. Pivanova, G. Lukina, Y. Sigidin, A. Smirnov, K. Kuzikyants, A. Kuznetsova. Nasonova Research Institute of Rheumatology, MOSCOW, RUSSIA, Moscow, Russian Federation

Background: Rheumatoid arthritis (RA) is a chronic inflammatory disease characterized by synovial hyperplasia, mononuclear cell infiltration, bone erosion and joint destruction. Antirheumatic treatment plays a important role in controlling the inflammation of rheumatoid arthritis and in minimizing joint damage. Rituximab - it is a chimeric monoclonal antibody that targets the CD20 molecule expressed on the surface of B cells. It has been successfully used to treat rheumatoid arthritis, and it is worth noting that his antidestructive effect sometimes does not meet the clinical.
Objectives: to assess clinical and antidestructive effect of Rituximab (RTX) in patients with rheumatoid arthritis (RA).

Methods: 108 patients (pts) with RA, most of them were middle-age women with high disease activity (mean DAS28 6,1 11,04 , RF-positive 77\%, ACCP-positive $83 \%$ ) treated with RTX (1000 mgx2 or $500 \mathrm{mgx}$ ). Clinical effect was evaluated by EULAR criteria; radiological progression by SVH method.

Results: 104 patients were treated by RTX $(500 \times 2$ or $1000 \times 2)$, had good response: after 48 week of treatment clinical improvement was achieved in $65 \%$ pts, good and moderate response by EULAR criteria in $23 \%$ and $42 \%$ pts accordingly. Noteworthy, after 12 months of treatment RTX radiological progression was absent in $50 \%$ pts with high disease activity.

Conclusions: RTX treatment slowed joint damage without clinical improvement. Clinical and antidestructive results did not always coincide which suggests different mechanisms of clinical and antidestructive effects of anti-B-cell therapy Disclosure of Interest: None declared

DOI: 10.1136/annrheumdis-2017-eular.6524

\section{SAT0191 PATTERNS OF INTERSTITIAL LUNG DISEASE IN RHEUMATOID ARTHRITIS AND ABATACEPT. MULTICENTER STUDY OF 63 PATIENTS}

C. Fernández-Díaz ${ }^{1}$, S. Castañeda ${ }^{2}$, C. Ojeda $^{3}$, A. Olivé $^{4}$, P. Carreira ${ }^{5}$,

T. Perez-Sandoval ${ }^{6}$, M. Retuerto $^{7}$, E. Cervantes $^{8}$, S. Rodriguez $^{4}$, B. Robles ${ }^{9}$,

B. Hernandez ${ }^{3}$, A. Urruticoechea ${ }^{10}, \mathrm{O}_{\text {Maiz }}{ }^{11}$, D. Palma ${ }^{12}$, L. Arboleya ${ }^{13}$,

G. Bonilla ${ }^{14}$, I. Rodriguez ${ }^{15}$, C. Delgado ${ }^{16}$, R. Exposito ${ }^{17}$, A. Ruibal ${ }^{18}$,

J. Blanco ${ }^{19}, \mathrm{M}^{2}$ Rodriguez ${ }^{20}, \mathrm{~J}$. Bernal ${ }^{21}$, P. Vela ${ }^{21}$, B. Alvarez ${ }^{22}$, C. Fito ${ }^{23}$,

J. Narvaez ${ }^{24}$, M. Moreno ${ }^{25}$, M. Lopez ${ }^{26}$, N. Mena ${ }^{27}$, S. Romero ${ }^{28}$,

C. Aguilera ${ }^{29}$, S. Ordoñez ${ }^{30}$, I. Villa ${ }^{31}$, V. Mora ${ }^{1}$, M. Gonzalez-Gay ${ }^{1}$,

J. Hernandez ${ }^{1}$, R. Blanco $1 .{ }^{1} H U M V$, Santander; ${ }^{2} H$. Princesa, Madrid; ${ }^{3} \mathrm{H}$

Macarena, Sevilla; ${ }^{4} \mathrm{H}$ Trias, Barcelona; ${ }^{5} \mathrm{H} 12$ Octubre, Madrid; ${ }^{6} \mathrm{H} ;{ }^{7} \mathrm{H}$., Leon;

${ }^{8} \mathrm{H}$, Santiago; ${ }^{9} \mathrm{H}$. P Hierro, Madrid; ${ }^{10} \mathrm{H}$, Ibiza; ${ }^{11} \mathrm{H}$, Donostia; ${ }^{12} \mathrm{H}$, Lorca; ${ }^{13} \mathrm{H}$,

Oviedo; ${ }^{14} \mathrm{H}$. Paz, Madrid; ${ }^{15} \mathrm{H}$, Vigo; ${ }^{16} \mathrm{H}$., Zaragoza; ${ }^{17} \mathrm{H}$., Laredo; ${ }^{18} \mathrm{H}$., Araba;

${ }^{19} \mathrm{H}$. Basurto, Bilbao; ${ }^{20} \mathrm{H}$., Ourense; ${ }^{21} \mathrm{H}$., Alicante; ${ }^{22} \mathrm{H}$, Araba; ${ }^{23} \mathrm{H}$, Pamplona;

${ }^{24} \mathrm{H}$. Bellvitge, Barcelona; ${ }^{25} \mathrm{H}$.Arrixaca, Murcia: ${ }^{26} \mathrm{HVHebron}$, Barcelona: ${ }^{27} \mathrm{H}$,

Malaga; ${ }^{28} \mathrm{H}$, Pontevedra; ${ }^{29} \mathrm{H}$, Sevilla; ${ }^{30} \mathrm{H}$, Lleida; ${ }^{31} \mathrm{H}$, Sierrallana, Spain

Background: Disease modifying antirheumatic drugs (DMARDs) such as methotrexate (MTX), leflunomide (LFN) or antiTNF $\alpha$ have been implicated in development/exacerbation of Interstitial lung disease (ILD)of rheumatoid arthritis (RA). Several radiological patterns of ILD have been described: i) usual interstitial pneumonia (UIP), ii) nonspecific interstitial pneumonia (NSIP), iii) obliterating bronchitis (OB), and iv) Organized pneumonia (OP)

Objectives: To assess the response to Abatacept (ABA) in these patterns of ILD Methods: Multicenter study of RA-ILD treated with ABA. ILD was diagnosed by high-resolution CT scan (HRCT) and classified in radiological patterns (Travis et al). We consider 3 subgroups: a) UIP, b) NSIP and c) "other" (OB, OP or mixed). ABA was used at iv or sc standard dose. We assessed: a) Dyspnea (Medical Research Council-modified scale; significant variations $\geq 1$ ); B) Respiratory function tests; significant changes $\geq 10 \%$ in forced vital capacity (FVC) and $\mathrm{DLCO} \leq 10 \%$, c) HRCT, d) DAS28. A comparative study was performed for the quantitative (U-Mann-Whitney) and qualitative variables (Fisher test) between the baseline and 3, 6 and 12 months.

Results: We included 63 patients (27 women/36 men), mean age; $63.1 \pm 9.6$ years. At ABA onset the RA had a median evolution of 6.8 [2-13.6] years and the ILD of 1 [0.3-3.03]. RA was seropositive in $85.7 \%$. The diagnosis of ILD was confirmed by biopsy ( $n=18)$. The ILD was related to DMARDs: MTX (4), etanercept (3), adalimumab (3), certolizumab (2), Infliximab (1). ABA was used in monotherapy (26) or combined with other DMARDs (37); LFN (15), Cyclosporin (1), sulfasalazine (4), MTX (6), hydroxychloroquine (10), azathioprine (4), chloroquine (1). Table 1 shows the evolution in the available cases. A significant improvement in dyspnea and HRCT was observed in the NIU type. DLCO remained stable in most patients regardless of the radiological pattern. The activity of RA (DAS28) also improved.

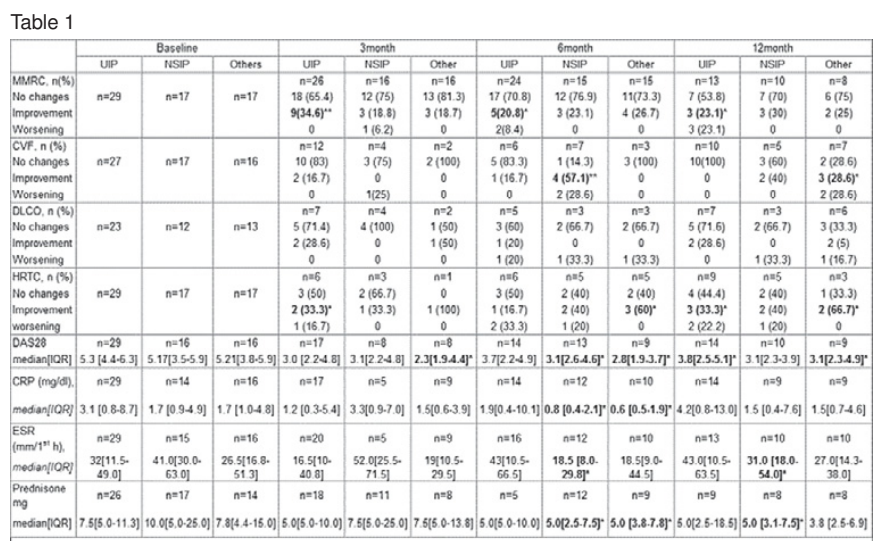

